\title{
Transatlantica
}

Revue d'études américaines. American Studies Journal

\section{Jacques Pothier. Les Nouvelles de Flannery O'Connor.}

Editions du Temps : Nantes, 2004.

\section{Aurélie Guillain}

\section{(2) OpenEdition}

Journals

Édition électronique

URL : http://journals.openedition.org/transatlantica/600

DOI : $10.4000 /$ transatlantica.600

ISSN : $1765-2766$

Éditeur

AFEA

Référence électronique

Aurélie Guillain, « Jacques Pothier. Les Nouvelles de Flannery O'Connor. », Transatlantica [En ligne], 1 । 2006, mis en ligne le 25 mars 2006, consulté le 29 avril 2021. URL : http://journals.openedition.org/ transatlantica/600 ; DOI : https://doi.org/10.4000/transatlantica.600

Ce document a été généré automatiquement le 29 avril 2021.

\section{(c) (i) $\odot$}

Transatlantica - Revue d'études américaines est mis à disposition selon les termes de la licence Creative Commons Attribution - Pas d'Utilisation Commerciale - Pas de Modification 4.0 International. 


\section{Jacques Pothier. Les Nouvelles de Flannery O'Connor.}

Editions du Temps : Nantes, 2004.

Aurélie Guillain

1 Dans cet ouvrage, J. Pothier présente de manière synthétique les deux recueils de nouvelles de Flannery O'Connor qui ont été rassemblés de manière posthume dans The Collected Short Stories. Il y dégage les deux grandes figures de la suffisance qui se pavanent dans ces nouvelles: la figure du Pharisien et celle de l'intellectuel progressiste, deux personnages également convaincus d'occuper la place de choix au sein de hiérarchies qu'ils ont eux-mêmes conçues mais qui, au terme des intrigues, perdent invariablement leur équilibre physique et leurs certitudes morales. La perte d'équilibre, la dislocation, le déplacement sont d'emblée isolés comme les images concrètes qui permettent de figurer l'intrusion du surnaturel dans une écriture qui ne déserte jamais le monde sensible.

2 J. Pothier renvoie très vite le lecteur à l'intertexte biblique, et plus particulièrement à l'évangile de Marc (10:18-19), pour définir la double visée, à la fois pessimiste et optimiste, de l'écriture de O'Connor. Il montre comment cette écriture déconcertante radicalise constamment l'opposition entre logique éthique et logique religieuse, en démasquant les «bonnes gens", ceux qui se croient sauvés, meilleurs, plus lucides et plus généreux que les autres, et qu'elle impose à ces personnages une violente confrontation avec un Dieu violent qui n'entre pas dans les comptabilités humaines, au sens où il ne tient aucun compte de leurs bonnes actions ou de leurs rationalisations. Il montre ainsi comment l'écriture de O'Connor prolonge la critique luthérienne des bonnes œuvres, mais aussi la réflexion de Kierkegaard sur la nécessité de maintenir séparés les plans éthiques et religieux. J. Pothier insiste à juste titre sur la conscience aiguë qu'avait O'Connor de son lectorat, et sur les stratégies provocatrices qu'elle adopte pour contrarier les présupposés humanistes de celui-ci. Par ailleurs, et c'est l'originalité de la lecture présentée ici, la stratégie comique de O'Connor n'est jamais sous-estimée : par comique, il faut entendre non seulement des procédés comiques qui sont ici analysés avec précision, mais aussi la comédie au sens où Northrop Frye 
l'entend, notamment au sujet de la Divine Comédie de Dante : un texte dont la conclusion est heureuse, même si pour la trouver heureuse il faut adopter une logique qui est étrangère à la créature humaine. Le chapitre consacré à la sensualité chez O'Connor ( «L Corps dans l'œuvre, le corps de l'œuvre » et celui qui traite de "l'enchantement du monde » («Paysages au Soleil») mettent au jour des aspects optimistes ou des éléments merveilleux qui sont parfois négligés par la critique française. Celle-ci, souvent soucieuse de distinguer avec soin l'écriture fictionnelle de l'écriture apologétique, est en effet souvent attentive aux noirceurs et aux cruautés d'un écrivain pour qui l'écriture serait avant tout un exercice de haine ou de colère. Dans le champ de la critique française sur O'Connor, cet ouvrage se distingue donc par son approche nuancée.

3 Par ailleurs, le souci pédagogique est constamment sensible dans un texte qui définit clairement et précisément les termes critiques qu'il emploie. Ce souci est également sensible dans les notes de bas de page qui renvoient avec honnêteté aux critiques qui ont précédé l'auteur dans l'analyse des textes de O'Connor. Lorsqu'il se penche sur des nouvelles individuelles, ses analyses sont souvent fines et elles éclairent de nombreux détails de manière originale. On pense notamment à l'analyse fouillée du changement de ton dans «A Good Man is Hard To Find » (64-68) et à l'étude des signifiants flottants dans «Good Country People» (116-120). Un tel ouvrage sera utile au lecteur qui cherche une introduction générale aux nouvelles de Flannery O'Connor, mais aussi à celui qui s'intéresse à une microlecture des textes.

\section{AUTEUR}

\section{AURÉLIE GUILLAIN}

Université de Toulouse-le Mirail 